\title{
The Digital Future of Education
}

edited by Johannes Britz, Michael Zimmer

\section{Editor of this issue:}

\author{
Johannes Britz \\ PhD, Provost and Vice Chancellor for Academic Affairs \\ University of Wisconsin-Milwaukee, USA \\ Email: britz@uwm.edu

\section{Michael Zimmer} \\ $\mathrm{PhD}$, Associate Professor, School of Information Studies, \\ Director, Center for Information Policy Research \\ University of Wisconsin-Milwaukee, USA \\ Email: zimmerm@uwm.edu
}

\section{Editors of IRIE}

Prof. Dr. Rafael Capurro (Editor in Chief), International Center of Information Ethics (ICIE) Redtenbacherstr. 9, D-76133 Karlsruhe, Germany E-Mail: rafael@capurro.de

Prof. Dr. Johannes Britz, University of Wisconsin-Milwaukee, USA and University of Pretoria, South Africa

E-Mail: britz@uwm.edu

Prof. Dr. Thomas Hausmanninger, University of Augsburg, Germany, Universitätsstr. 10 , D-86135 Augsburg E-Mail: thomas.hausmanninger@kthf.uni-augsburg.de
Dr. Michael Nagenborg, Assistant Professor for Philosophy of Technology Dept. of Philosophy, University of Twente, NL E-Mail: M.H.Nagenborg@utwente.nl

Prof. Dr. Makoto Nakada, University of Tsukuba, Japan, Tennodai, Tsukuba, 305-8577 Ibaraki E-Mail: nakadamakoto@msd.biglobe.ne.jp

Dr. Felix Weil, QUIBIQ, Stuttgart, Germany, Heßbrühlstr. 11, D-70565 Stuttgart E-Mail: felix.weil@quibiq.de 